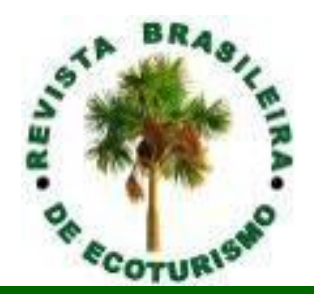

\title{
Turismo sustentável: perspectiva socioambiental como geração de valor em empreendimentos hoteleiros de Barreirinhas (MA)
}

\section{Sustainable tourism: the social-environmental perspective as generation of value in hotel development in Barreirinhas (MA, Brazil)}

\author{
Rosélis de Jesus Barbosa Câmara, Raimunda Rocha Reis, Rozuila Neves Lima
}

\begin{abstract}
RESUMO: A atividade do turismo representa um fator notável de desenvolvimento econômico e social, uma vez que possui grande capacidade de impacto e é capaz de promover influências em diversos setores e aspectos de um local ou região. $O$ município de Barreirinhas/MA, considerado o principal portão de entrada para o Parque Nacional dos Lençóis Maranhenses, destaca-se por sua notabilidade turística. Assim, a presente pesquisa teve como propósito investigar a sustentabilidade socioambiental no contexto dos empreendimentos de hospedagem de Barreirinhas/MA, posto que a sustentabilidade influencia fatores relevantes como: a preservação dos atrativos turísticos e dos recursos naturais, o relacionamento com os stakeholders, a redução de custos e a oportunidade de captação de demanda por nichos. Para o estudo, foi utilizado o método de pesquisa de campo, com caráter exploratório e abordagem quali-quantitaiva. A investigação constatou que os empreendimentos de hospedagem de Barreirinhas/MA ainda não atingiram o nível desejado de sustentabilidade. Assim, defende-se a necessidade de se desenvolver uma atividade turística pautada na sustentabilidade, no cuidado com o ecossistema natural e o ambiente social, essenciais ao município.
\end{abstract}

PALAVRAS CHAVE: Turismo; Barreirinhas; Empreendimentos Hoteleiros; Geração de Valor; Sustentabilidade.

ABSTRACT: Tourism activity represents a notable economic and social development factor, since it has great impact capacity and is capable to promote influences in different sectors and aspects of a place or region. The municipality of Barreirinhas/MA, considered the main entrance gate to the Lençóis Maranhenses National Park, stands out for its tourist notability. Thus, the purpose of this research was to investigate socio-environmental sustainability in the context of Barreirinhas/MA hosting project, since sustainability influences relevant factors, such as the preservation of tourist attractions and natural resources, the relationship with stakeholders, the reduction of costs and the opportunity to capture demand for niches. For the study, the field research method was used, with an exploratory character and a qualitative and quantitative approach. The investigation found that Barreirinhas /MA hosting projects have not yet reached the desired level of sustainability. Thus, it is necessary to develop a tourist activity based on sustainability, care for the natural ecosystem and the social environment, essential to the municipality.

KEYWORDS: Tourism; Barreirinhas; Hotel Developments; Value Generation; Sustainability. 


\section{Introdução}

O turismo é, antes de qualquer processo, um fenômeno que expressa o movimento de pessoas, grupos ou massas a determinado local por algo que os atraem. Em função da sua grande movimentação econômica, por ser um dos principais setores da economia global em geração de emprego e renda e atração de investimentos (OMT apud BRASIL, 2018, p.22), a atividade turística pode se tornar um pertinente fator de desenvolvimento econômico e social de uma localidade, proporcionando aspectos positivos ao destino. Por outro lado, a atividade pode gerar impactos negativos, relacionados ao uso dos recursos e atrativos naturais, além de maximizar problemas sociais, se não for desenvolvida de maneira sustentável, conforme se têm descrito em estudos a esse respeito.

A região dos Lençóis Maranhenses, por sua vez, apresenta-se como um relevante destino turístico natural, onde a atividade tem se desenvolvido enquanto fenômeno por meio de seu notável atrativo, que é o Parque Nacional dos Lençóis Maranhenses. Nesse contexto, o município de Barreirinhas se destaca, constituindose como um local de apoio ao turismo e à visitação da região por meio da disponibilização e do desenvolvimento de infraestrutura e de serviços de apoio à atividade. Diante disso, a importância da sustentabilidade turística para a cidade é corroborada, pois, compreende-se a conjugação dos fatores econômicos, ambientais e sociais na localidade.

A partir desse entendimento, os meios de hospedagem assumem importância significativa enquanto prestadores de serviços turísticos na cidade, fornecendo um serviço essencial para o desempenho do turismo na região. Considerando a relevância desses empreendimentos para a oferta e para os produtos turísticos, busca-se compreender a sustentabilidade nessas organizações a partir de sua perspectiva socioambiental como estratégia de geração de valor, por meio do seguinte questionamento: como essa perspectiva configura-se como estratégia de geração de valor nesses empreendimentos? Para responder a essa questão, foi descrito o contexto socioambiental desses empreendimentos e verificada sua influência na atuação dos mesmos, com vistas a demonstrar como a perspectiva socioambiental gera valor a esses empreendimentos da cidade.

$\mathrm{Na}$ intenção de demonstrar a importância da perspectiva socioambiental como estratégia de geração de valor para os empreendimentos de hospedagem na cidade de Barreirinhas, utilizou-se de pesquisa de campo como instrumento de investigação. Quanto aos objetivos, a pesquisa caracteriza-se como exploratória, e quanto à abordagem, o estudo está classificado como qualitativo e quantitativo, ou quali-quanti, por apresentar um tratamento avaliativo e de descrição analítica.

Nesse sentido, foi realizado, inicialmente, um levantamento bibliográfico e documental com vistas à compreensão do assunto e da realidade do local estudado. Além de produções bibliográficas, foram consultadas também fontes documentais, como leis e planos, para a abordagem teórica e prática do tema e da contextualização do objeto estudado, que se refere ao conjunto dos empreendimentos hoteleiros da cidade de Barreirinhas - MA. 


\section{Turismo e Sustentabilidade}

A análise de Feil e Schreiber (2017) sobre sustentabilidade e desenvolvimen-to sustentável expõe que o progresso da civilização ocidental teve seu auge entre os anos de 1750 e 1900. Nesse período, houve a consolidação do progresso da ciên-cia, em que se identificou o domínio da natureza, o que culminou no evento da Revolução Industrial. Entretanto, já no final do século XVIII, alguns aspectos negativos oriundos desse processo foram surgindo, como desemprego, pobreza e doenças.

É nesse contexto que começa a ser desenvolvida a perspectiva da sustentabilidade. Os referidos autores citam que "[...] as diversas discussões atreladas aos termos sustentável, sustentabilidade e desenvolvimento sustentável ocorreram visando à obtenção do bem-estar humano em longo prazo por meio da gestão do sistema ambiental humano" (FEIL; SCHREIBER, 2017, p. 668).

$\mathrm{Na}$ mesma perspectiva, os autores Bacha, Santos e Schaun (2010, p. 1) em artigo que discute as considerações teóricas sobre o conceito de sustentabilidade, dispõem que:

o tema sustentabilidade tem apresentado crescente interesse entre pesquisadores acadêmicos. Sua importância se deve principalmente à atenção despertada face às mudanças climáticas causadas pela ação predatória do homem no meio ambiente causando uma emergência planetária. Finalmente se reconhece o preço de fatores como o meio ambiente, o impacto sobre as comunidades e a longevidade dos funcionários, o que pode significar uma visão mais ampla de sustentar a lucratividade da empresa ao longo do tempo.

Percebe-se que a sustentabilidade parte de uma abordagem ambiental e social em direção aos contextos dessa relação na qual o aspecto econômico demonstra-se como principal. Nesse sentido, a má qualidade ou insuficiência do ambiente natural e do meio social afeta diretamente o desempenho do fator econômico que, portanto, encontra-se condicionado a essas perspectivas.

A partir da problemática apresentada em função do gerenciamento inadequado dos recursos ambientais e quanto à importância dos aspectos sociais para o desenvolvimento econômico e a qualidade de vida no planeta, volta-se a atenção para o estudo da situação com foco inicialmente nas questões ambientais. Assim, tais autores dispõem ainda que:

a questão da sustentabilidade ambiental passou a ocupar lugar de importância no debate acadêmico e político, sobretudo a partir do final dos anos 1960, porém, as duas últimas décadas testemunharam a emergência do discurso da sustentabilidade como a expressão dominante no debate que envolve as questões de meio ambiente e de desenvolvimento social em sentido amplo (BACHA; SANTOS; SCHAUN, 2010, p. 5).

O período mencionado da descrição relaciona-se também ao contexto em que se intensifica a busca por atividades de lazer por meio do turismo. Logo, compreendese a relação da temática sustentável à atividade, que se desenvolveu, dentre outros aspectos, como forma de melhoria da qualidade de vida, afetada pelo stress do ritmo acentuado do trabalho e do cenário urbano. 
Almeida e Abranja (2009, p. 23), ao tratarem sobre Sustentabilidade e Turismo, afirmam também que "[...] a sustentabilidade tem sido um conceito de crescente preocupação, principalmente a partir da segunda metade do século $X X$, período que coincide com o crescimento acentuado da atividade turística".

Ainda nessa conjuntura, Dias (2007) aborda a atividade como ação econômica que se desenvolveu como consequência da revolução industrial e sob o aspecto do fenômeno de massas. O autor cita que essa revolução introduziu na sociedade moderna um modelo econômico cujo objetivo principal é a geração de renda por meio da expropriação e exploração dos recursos naturais e que, de fato, esse modelo, o qual identifica como capitalismo industrial, promoveu o desenvolvimento das sociedades, baseado na intensa apropriação dos recursos naturais, proporcionando melhora nas condições de vida em relação à época anterior, porém, ocasionou um intenso crescimento populacional, que passou a exercer pressão cada vez maior sobre os recursos naturais.

Assim, surgiu a necessidade de se pensar um modelo de desenvolvimento alternativo ao modelo tradicional, que culminou na expressão desenvolvimento sustentável durante a Conferência das Nações Unidas sobre o Meio Ambiente e o Desenvolvimento (a Eco-92 ou Rio-92), que aconteceu no Rio de Janeiro - Brasil, no ano de 1992, e cuja ideia compreendia o atendimento das necessidades das gerações presentes sem comprometer esse direito às futuras gerações.

O desenvolvimento sustentável do turismo adquire, nesse contexto, uma função significativa. Segundo Hanai (2011), essa expressão foi sugerida por Butler (1999) e refere-se ao turismo que é:

[...] desenvolvido e mantido em uma área (comunidade e ambiente) de uma forma e numa escala que permanece viável ao longo de um infinito período e não degrada ou altera o ambiente (físico e humano) em que existe para um grau que proíbe o desenvolvimento com êxito e o bem estar com outras atividades e processos (HANAI, 2011, p. 216).

O autor conclui a abordagem evidenciando por meio de KO (2005) que este desenvolvimento, portanto, é o "[...] que permite manter o estado saudável necessário para a sobrevivência do sistema (turístico) em condição desejável e com padrão aceitável em alto grau de qualidade" (HANAl, 2011, p. 27). Explicita também que há distinção entre "turismo sustentável" e "desenvolvimento sustentável", sendo o primeiro o objeto a ser alcançado e, o segundo, o processo para o alcance do primeiro. Assim, é importante operacionalizar o desenvolvimento sustentável do turismo para que se tenha o turismo sustentável (HANAl, 2011, p. 217). comentam:

Quanto a essa perspectiva, os autores Feil e Schreiber (2017, p. 678), também

O desenvolvimento sustentável é o processo que entra em cena com base em estratégias para aproximar o sistema ambiental humano ao nível de sustentabilidade com vistas a que a vida deste complexo sistema se harmonize e perpetue ao longo do tempo. Esta questão estratégica intenta a ruptura de paradigmas por meio de mudanças no entendimento e posicionamento cultural da sociedade. 
Segundo a Organização Mundial do Turismo (OMT, 2003), o turismo sustentável é, por sua vez, aquele que "[...] atende às necessidades dos turistas de hoje e das regiões receptoras, ao mesmo tempo em que protege e amplia as oportunidades para o futuro" (OMT, 2003 apud HANAI, 2011, p. 211). Ainda de acordo com Hanai (2011, p. 211), a OMT (2003, p. 212) "[...] reconhece que as diretrizes para o desenvolvimento sustentável do turismo e as práticas de gestão sustentáveis são aplicáveis a todas as formas de turismo, em todos os tipos de destino". Assim, dispõe sobre os princípios de sustentabilidade, sendo estes identificados como os aspectos ambientais, econômicos e socioculturais do desenvolvimento turístico e que estabelecem entre si um equilíbrio adequado para garantir sua sustentabilidade em longo prazo (HANAI, 2011, p. 2012).

Isto posto, compreende-se, portanto, que, para haver um turismo sustentável é essencial atentar-se para o seu desenvolvimento, que deve acontecer com base na sustentabilidade, 0 que possibilita que a atividade continue proporcionando experiências de qualidade, garantindo, ao mesmo tempo, sua sobrevivência em um dado destino.

\section{A Perspectiva Socioambiental como Estratégia de Geração de Valor em Meios de Hospedagem}

Com relação ao significado de estratégia, no contexto da organização empresarial, Miranda (2017, p. 8) a descreve como "[...] um processo de maturação e evolução natural da complexa atividade da gestão de negócios condicionada pelos desenvolvimentos tecnológicos, econômicos, sociais e ambientais", e que compreende toda a organização, estando presente em suas mais diversas áreas, desde o produto à produção, desde o marketing à logística, desde os processos à gestão de ativos, desde as pessoas à marca do empreendimento.

O autor apresenta a definição de Chandler (1998) para quem a estratégia é "[...] a determinação das metas e objetivos básicos empresariais em longo prazo, bem como a adoção de cursos de ação e alocação de recursos necessários à consecução dessas diretrizes" (CHANDLER apud MIRANDA, 2017, p. 10). Miranda (2017) comenta a respeito da criação de valor, a qual pode ser identificada por meio de três formas principais: liderança ou predominância por meio dos custos; diferenciação no mercado; e captação de demandas por nichos (PORTER, 1985 apud MIRANDA, 2017).

No que concerne ao conceito de valor, este se encontra, no ambiente empresarial, relacionado à categoria dos recursos classificados como ativos intangíveis, chamados também de abstratos. Assim, expressa Miranda (2017, p. 22):

[...] ativos intangíveis ou abstratos, abrangem elementos relacionados à reputação empresarial e desempenham função relevante na vantagem ou desvantagem competitiva assim como no valor da empresa, exemplificado por marcas, nomes, culturas, conhecimentos tecnológicos, patentes, aprendizagem, experiência, dentre outros. 
Desse modo, dimensiona-se o peso que a estratégia de geração de valor pode proporcionar à empresa, uma vez que influencia ativos essenciais ao seu posicionamento e sua manutenção no mercado, incluindo-se, nesse contexto, as empresas turísticas de hospedagem. Com relação a esses empreendimentos, a lei no 11.771, de 17 de setembro de 2008, que estabelece a Política Nacional de Turismo, dispõe que:

consideram-se meios de hospedagem os empreendimentos ou estabelecimentos, independentemente de sua forma de constituição, destinados a prestar serviços de alojamento temporário, ofertados em unidades de frequência individual e de uso exclusivo do hóspede, bem como outros serviços necessários aos usuários, denominados de serviços de hospedagem, mediante adoção de instrumento contratual, tácito ou expresso, e cobrança de diária (BRASIL, 2008, s/p).

Os meios de hospedagem, enquanto parte elementar da oferta turística de uma localidade e, portanto, dos produtos turísticos de uma região, ao ofertarem um de seus serviços cruciais, que é a hospedagem, atuam como agentes imprescindíveis para o desenvolvimento turístico de um destino, com a possibilidade de promoverem importantes influências ao adotar uma cultura e práticas sustentáveis.

Nesse viés, o desenvolvimento turístico baseado na sustentabilidade torna-se estratégico para esses empreendimentos, sendo essa forma de desenvolvimento turístico essencial para a sustentabilidade do destino e, por isso, fundamental para a sobrevivência e competitividade das empresas do setor de hospedagem. Segundo Cardoso e Figueiredo (2016, p. 51):

O turismo e, nesse âmbito, a hotelaria são segmentos em expansão que dependem diretamente da atratividade exercida pelo meio ambiente saudável, pela preservação das comunidades e pelo enaltecimento da cultura e da história locais. Com ações inovadoras voltadas para a sustentabilidade, torna-se possível agregar valor aos serviços gerados por essa indústria, em uma via de mão dupla em que as empresas hoteleiras ganham diretamente e indiretamente.

Partindo dessa visão, compreende-se, que a sustentabilidade promove maior valor aos meios de hospedagem, posto que passam a compartilhar de um destino com melhor qualidade ambiental e social e, desta forma, com melhores produtos turísticos. Além de promover melhor qualidade à oferta turística, a sustentabilidade promove valor ao empreendimento e ao seu serviço, considerando que as práticas sustentáveis refletem diretamente na redução de custos, como a eficiência energética e a reutilização de recursos; e a postura sustentável, por sua vez, permite a captação de demanda por nichos, além de contribuir com a reputação da empresa no mercado.

Assim, a sustentabilidade adquire um conceito estratégico importante para a competitividade da empresa e para os produtos do destino. A esse respeito, Porto e Santos (2013) consideram como estratégia do desenvolvimento sustentável aquela que corresponde "ao engajamento e ao forte senso de comprometimento da empresa no enfrentamento dos problemas e dos desafios socioambientais da sociedade" e 
que, "por sua natureza holística, tal estratégia serve de pano de fundo às demais e baliza a intenção de perenidade dos negócios" (PORTO; SANTOS, 2013, p. 155). Desse modo, os autores compartilham também a ideia de que a estratégia de desenvolvimento sustentável "representa uma estratégia alicerçada no compartilhamento e consenso de visões de futuro no ambiente interno em direção à inovação e à melhoria das condições do ambiente natural' (PORTO; SANTOS, 2013, p. 155).

Cardoso e Figueiredo (2016) expressam que as inovações baseadas nos princípios da sustentabilidade conduzem ao desempenho sustentável nas empresas, constituindo o que se denominam de "vantagem competitiva sustentável". Oliveira e Rossetto (2014, p. 552) descrevem que:

\begin{abstract}
aspectos inovadores quanto à sustentabilidade ambiental se incluídos nas estratégias, podem tornar a atuação ou compromisso ambiental dos hotéis em uma fonte de vantagem competitiva. Um empreendimento com boa gestão socioambiental obterá alta lucratividade, melhor condição para alocar recursos e desenvolver atividades e práticas proativas, isto gera um ciclo virtuoso com a performance econômica e que se reforça com o tempo (OLIVEIRA; ROSSETTO, 2014, p. 552).
\end{abstract}

A partir dessas abordagens, compreende-se que a atenção ao ambiente se torna também necessária, visto que é o território onde a atividade do turismo acontece e que tem a capacidade de influenciá-lo diretamente. Essa visão traduz-se numa espécie de simbiose, na qual a atividade do turismo depende do ambiente e de seus recursos para ser mantida, incluindo, nesse sentido, os aspectos sociais que representam a comunidade local.

Os empreendimentos de hospedagem fazem parte desse contexto, contribuindo para a oferta dos produtos turísticos no destino e gerando emprego, trabalho e renda no local. Os meios de hospedagem, enquanto prestadores de serviços essenciais à oferta de produtos turísticos, são agentes fundamentais neste processo ao contribuírem para a oferta de produtos competitivos por meio de sua cultura e práticas sustentáveis. Assim, a sustentabilidade é determinante para o negócio da organização, pois agrega valor a ele por meio do impacto na redução dos custos e gastos da organização ao adotar práticas sustentáveis de utilização dos recursos; por meio de um bom relacionamento com seus stakeholder ${ }^{1}$, que são os fornecedores, parceiros da atividade, clientes e comunidade, o que confere ao negócio diferenciação no mercado; e por meio da possibilidade de captação de demanda por nichos, representada por clientes que levam em consideração empreendimentos a partir de suas práticas e cultura sustentáveis.

Desta maneira, o empreendimento desenvolve a competitividade de seus serviços por meio da melhor utilização dos recursos naturais e da consequente durabilidade destes, promovendo, também, melhor qualidade e competitividade aos seus serviços e aos produtos turísticos da região.

\title{
O Lócus da Pesquisa: Barreirinhas e o Fenômeno do Turismo
}


Barreirinhas é um município de grande potencial para a sustentabilidade da região do Parque Nacional dos Lençóis Maranhenses - PNLM -, ou PARNA Lençóis, instituído no ano de 1981 por meio do Decreto-lei de no 86.060, com o objetivo principal de "[...] proteger a flora, a fauna e as belezas naturais existentes no local, ficando sujeito ao regime especial do Código Florestal, instituído pela Lei no 4.771, de 15 de setembro de 1965" (BRASIL, 1981, s/p).

O município se destaca, dentre outros fatores, por comportar grande parte do PARNA e por apresentar áreas com rios e bacias essenciais ao zoneamento da unidade de conservação. Portanto, pensar e adotar o conceito de sustentabilidade é imprescindível ao turismo do município, intitulado de "Capital dos Lençóis Maranhenses", e que apresenta um efervescente e prospectivo mercado nesse sentido.

Situado no litoral ocidental do Maranhão, o município de Barreirinhas é composto por um conjunto de recursos e atrativos naturais formados por rios, mangues, praias, dunas e lagoas interdunares. Essas características concedem notabilidade regional e turística ao município. O nome Barreirinhas originou-se em referência às barreiras de argila encontradas nas margens do rio Preguiças e que chegavam a atingir cerca de $10 \mathrm{~m}$ a $20 \mathrm{~m}$ de altura, envoltas por dunas de areias (IBAMA, 2003). Barreirinhas recebeu o título de município oficialmente em fins do século XIX, precisamente em 1835.

Barreirinhas possui uma área territorial de $3.026,540 \mathrm{~km}^{2}$, de acordo com dados do Instituto Brasileiro de Geografia e Estatística - IBGE - e uma população estimada em 61.828 pessoas ${ }^{2}$. Está situado a $246 \mathrm{~km}$ da capital São Luís, sua sede fica localizada à margem direita do Rio Preguiças, a $42 \mathrm{~km}$ da foz (GRAÇA, 2010), e é considerado o principal acesso à região dos Lençóis Maranhenses.

Acerca de seus atrativos, Martins (2008, p. 77) descreve que "[...] a parte norte do município é tomada pelas dunas e lagoas, no entanto, as características físicas do município indicam a existência de outras atratividades naturais". Nesse âmbito, "[...] 0 rio Preguiças, muito utilizado para a prática da atividade turística, é o principal rio da região dos Lençóis Maranhenses, e a origem de seu nome é atribuída ao fato de suas águas correrem preguiçosamente até a foz" (MARTINS, 2008, p. 66).

A cidade de Barreirinhas tem apresentado infraestrutura turística notável, com número crescente de empreendimentos que exercem função relevante na oferta de serviços e contribuem para o crescimento da cidade. Assim, o fenômeno do turismo tem apresentado diversos impactos na cidade e na região, promovendo diversas oportunidades de negócios e a possibilidade de desenvolvimento desta localidade, que é considerada a capital do destino Lençóis.

Entretanto, aquém de toda essa riqueza natural e potencialidade, o município apresenta, ainda, quanto ao fator social, um dos piores índices de Desenvolvimento Humano do país, correspondendo ao valor de 0,570 na última escala do programa, divulgada em 2010; o que representa um baixo índice de desenvolvimento, com a cidade ocupando a $4841^{\text {a }}$ posição entre os 5.565 municípios brasileiros, conforme dados e informações do PNUD, IPEA e FJP3.

Quanto ao fenômeno turístico na cidade, menciona-se que o impulsionamento do turismo na região ocorreu por meio de programas e ações do setor. Nessa conjuntura, cita-se a informação de Martins (2008, p. 62): "O Plano Integrado para o Desenvolvimento do Turismo do Estado do Maranhão designou o município de 
Barreirinhas para portal dos Lençóis Maranhenses como uma estratégia para o desenvolvimento deste polo turístico". (MARTINS, 2008, p. 62). Contudo, as ações iniciais referentes ao incentivo do turismo na região foram destituídas de um planejamento que permitisse o controle da atividade e sua efetividade com vistas ao desenvolvimento socioeconômico e à sustentabilidade do destino.

Com relação ao crescimento do turismo na cidade e na região, um fato considerado significativo foi a construção da rodovia MA - 402, concluída em 2002. Todos esses fatores, portanto, contribuíram para o crescimento do turismo na cidade, promovendo mudanças e impactos no contexto socioambiental do lugar.

A respeito das mudanças e impactos que esse crescimento propiciou à cidade, Graça (2010, p. 321) afirma ser "[...] fato inconteste que a era do turismo em Barreirinhas constitui um marco de intensas mudanças na paisagem urbana e rural, gestando uma 'nova ordem' socioespacial".

Neste quadro referente ao fenômeno do turismo na cidade de Barreirinhas, Rodrigues (2013) também discorre a respeito do desenvolvimento da atividade no local e seus efeitos para região e para a cidade. Assim, a autora menciona que:

a inserção dos Lençóis nas políticas territoriais empreendidas a partir de sua criação configurou a constituição de uma fronteira econômica e Barreirinhas, portão de entrada do Parque, foi inserida no processo de modernização regional, caracterizada, entre outros, pela instalação dos grandes equipamentos turísticos, como resorts e pousadas, bem como dos projetos e programas em níveis nacional, regional e estadual (RODRIGUES, 2013, p. 82).

De acordo com Rodrigues (2013, p. 82):

[...] a partir desse contexto, o investimento do setor público voltou-se para as políticas de promoção do destino Lençóis e se caracterizou por meio do Programa de Marketing do Plano Maior, cujo objetivo era criar uma imagem turística do Maranhão e aumentar o fluxo turístico.

A autora expressa os impactos do turismo na região, informando que a atividade promoveu mudanças positivas em função da infraestrutura estabelecida, como os equipamentos turísticos e a construção de estradas, e em função das ações de políticas públicas empreendidas no setor, em que nesse caso, correspondeu pragmaticamente a ações de promoção e marketing do destino. Entretanto, a atividade também produziu diversos impactos negativos, dentre os quais a autora cita a especulação imobiliária, que alterou a dinâmica do Rio Preguiças na cidade, o turismo descontrolado na região, a poluição e a ocupação irregular no território (RODRIGUES, 2013).

Verifica-se, portanto, que o fenômeno do turismo tem empregado muitas mudanças na cidade. Grande parte das quais é observada na paisagem e no cotidiano do lugar, que passou de uma simples e pacata cidade a um local de visitação intensiva, com crescente número de empreendimentos atraídos pela demanda e oportunidade de negócios do lugar.

Segundo dados do Portal Dinâmico do ICMBio4, a visitação em 2017 ao PARNA dos Lençóis Maranhenses, principal atrativo da região, correspondeu ao 
número de 89.540 visitantes. Em 2018, alcançou recorde de visitação, foram mais de 107 mil visitantes ao longo do ano (MTur, 2018).

A partir dessa perspectiva, compreende-se a importância do desenvolvimento sustentável para a região e para a cidade. Barreirinhas localiza-se em uma área estratégica de acesso ao PARNA, à região da Rota das Emoções e aos seus demais atrativos. Assim, apresenta a necessidade de se desenvolver enquanto local de serviços e de infraestrutura de apoio a uma oferta turística de qualidade, o que se dá a partir de investimentos no setor. Quanto a isso, conforme o sistema de formalização e legalização dos prestadores de serviços turísticos no Brasil, o CADASTUR $^{5}$, Barreirinhas apresenta o seguinte número de empreendimentos voltados para a oferta turística da região: 67 agências, 43 meios de hospedagem, 04 transportadoras turísticas e 09 empreendimentos do ramo de restaurantes, cafeterias, bares e similares.

Nessa tendência, os empreendimentos hoteleiros da cidade assumem destaque por serem parte básica da oferta turística da região e inserem-se nessa proposta de sustentabilidade. A partir da perspectiva socioambiental, é fundamental demonstrar como este conceito se apresenta no contexto desses empreendimentos, uma vez que propicia a geração de valor aos seus serviços, aos produtos e ao turismo da cidade, sendo, portanto, necessário ao desenvolvimento turístico da região. O município se destaca, dentre outros fatores, por comportar grande parte do PARNA e por apresentar áreas com rios e bacias essenciais ao zoneamento da unidade de conservação. Portanto, pensar e adotar o conceito de sustentabilidade é imprescindível ao turismo do município, intitulado de "Capital dos Lençóis Maranhenses", e que apresenta um efervescente e prospectivo mercado nesse sentido.

\section{A Perspectiva Socioambiental dos Empreendimentos de Hospedagem na cidade de Barreirinhas}

Dado o objetivo de descrever a perspectiva socioambiental dos empreendimentos de hospedagem na cidade de Barreirinhas, buscou-se compreender o nível de sustentabilidade desses empreendimentos utilizando-se, para isso, uma ferramenta de avaliação da sustentabilidade. Então, foi empregado o "Barômetro de Sustentabilidade do Turismo (BST)", que é um instrumento direcionado para a área de turismo e que foi desenvolvido por KO, em 2005, a partir do Barômetro de Sustentabilidade proposto por Prescott-Allen, em 2000 (CORDEIRO, 2008; SANCHES; SCHMIDT, 2016; SANTOS, S.; SANTOS P.; SEHNEM, 2016).

A ferramenta aborda as perspectivas ambiental e social na mensuração da sustentabilidade, considerando que a salubridade destes sistemas é que determinará a sustentabilidade como um todo no meio avaliado. Prescott-Allen (2001) sustenta que os valores monetários não são determinantes na mensuração da sustentabilidade, já que estes são consequências dos valores ambientais e sociais. Nessa ótica, compreende-se o pensamento do autor por meio da observação de que o crescimento em números financeiros de uma empresa ou organização não reflete por si só a qualidade do meio ambiente e do bem-estar social, ou seja, não reflete a sustentabilidade por essa perspectiva (KO, 2005, PRESCOTT- ALLEN, 2001 apud CORDEIRO, 2008; SANCHES; SCHMIDT, 2016).

Nesta mesma visão, o Barômetro de Sustentabilidade do Turismo, é aplicado a partir do entendimento de que para a sustentabilidade no turismo é necessário que as 
dimensões ambiental e social sejam fortemente sustentáveis, as quais influenciarão as atividades turísticas, sendo, portanto, suficientes para medir a sustentabilidade da atividade (CORDEIRO, 2008; SANCHES; SCHMIDT, 2016).

O BST, então, é constituído pelos sistemas ambiental e social, que representam os índices de bem-estar social e bem-estar ambiental, os quais são compostos por cinco indicadores, que possuem o valor de 20 pontos individuais e juntos formam as escalas totais, com valores correspondentes de 0 a 100 , informando, assim, o nível de sustentabilidade do meio avaliado, (Gráfico 1).

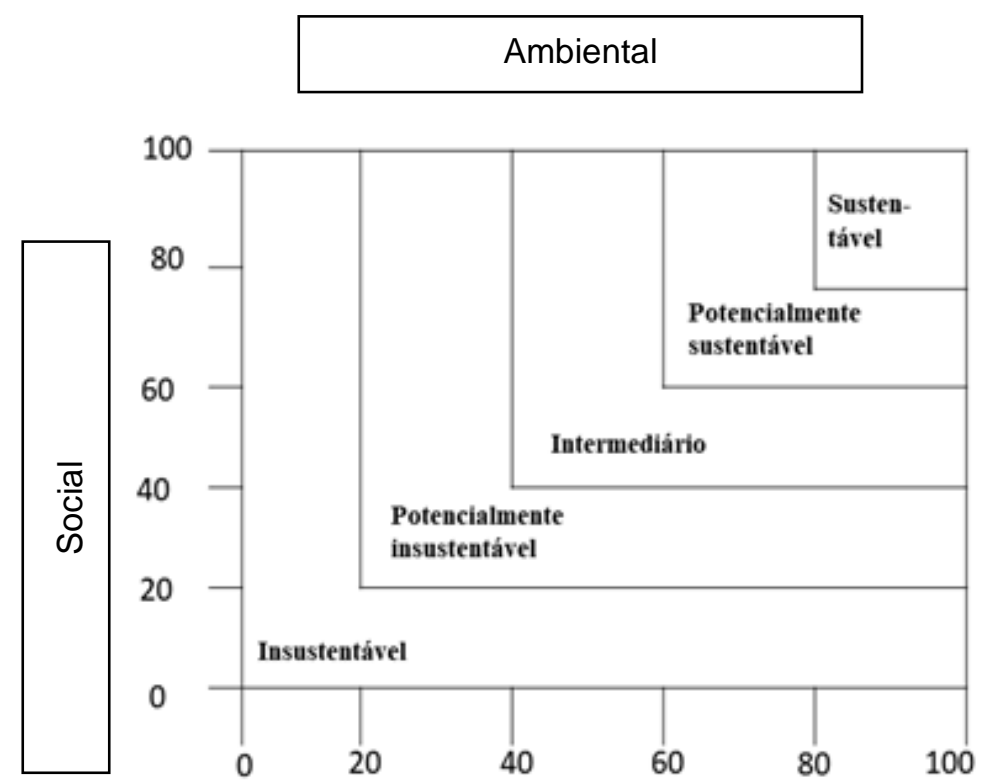

Gráfico 1: Barômetro de Sustentabilidade. Fonte: Cordeiro (2008), adaptado pelos autores (2018). Graph 1: Barometer of sustainable. Source: Cordeiro (2008), adapted by the authors (2018).

De acordo com a escala de performance da sustentabilidade, Cordeiro (2008) apresenta a seguinte leitura: o empreendimento estará no nível sustentável (desempenho desejável, objetivo completamente alcançado) se obtiver pontuação entre 81 a 100 pontos. Já o empreendimento que alcançar pontuação entre 61 a 80 pontos se enquadrará no nível potencialmente sustentável, com desempenho aceitável, objetivo quase alcançado. Se a pontuação do empreendimento estiver entre 41 a 60 pontos, este se enquadrará no nível intermediário, com performance neutra. De 21 a 40 pontos, o empreendimento configura-se no nível de potencialmente insustentável, com performance inaceitável Cordeiro (2008).

\section{As dimensões ambiental e social}

Para a descrição do contexto socioambiental dos empreendimentos e análise da sustentabilidade, a ferramenta BST aponta como compostos da dimensão ambiental cinco tópicos que indicam o nível de sustentabilidade da dimensão em questão, que é apresentada como ecossistema, conforme se demonstra, (Fluxograma 1). 
Fluxograma 1: Dimensão ambiental do BST. Fonte: Cordeiro, 2008; Sanches e Schmidt, 2016. Fluxograma 1: Environmental dimension of BST. Source: Cordeiro, 2008; Sanches and Schmidt, 2016.

No âmbito da dimensão ambiental, o indicador solo investiga questões como coleta seletiva, medidas para reduzir a produção de lixo, separação e encaminhamento para reciclagem dos resíduos sólidos produzidos pelo empreendimento. No indicador água, os itens observados são chuveiros e torneiras com regulagem de pressão e arejadores, sistema de captação e aproveitamento da água da chuva, sinalização em áreas comuns do empreendimento com dicas de consumo. No indicador "ar", é averiguado o aproveitamento de plantas regionais na decoração do ambiente, o incentivo ao uso de transportes e ações alternativas. Quanto às "espécies e população", são avaliadas questões como o apoio a projetos de preservação e cuidado com animais e plantas ameaçados de extinção, além de medidas de redução do consumo de papel. O indicador de "utilização de recursos", está direcionado para temporizadores ou sensores de presença, televisores com baixo consumo, ar-condicionado de baixo consumo, desligamento automático por cartão, geração de energia elétrica por painéis solares, aproveitamento da iluminação e ventilação natural do ambiente.

$\mathrm{Na}$ mesma linha de configuração, a dimensão social é composta de cinco tópicos que permitem avaliar o nível de bem-estar. Representada pelo domínio sociedade, a perspectiva social articula-se conforme se demonstra, (Fluxograma 2).

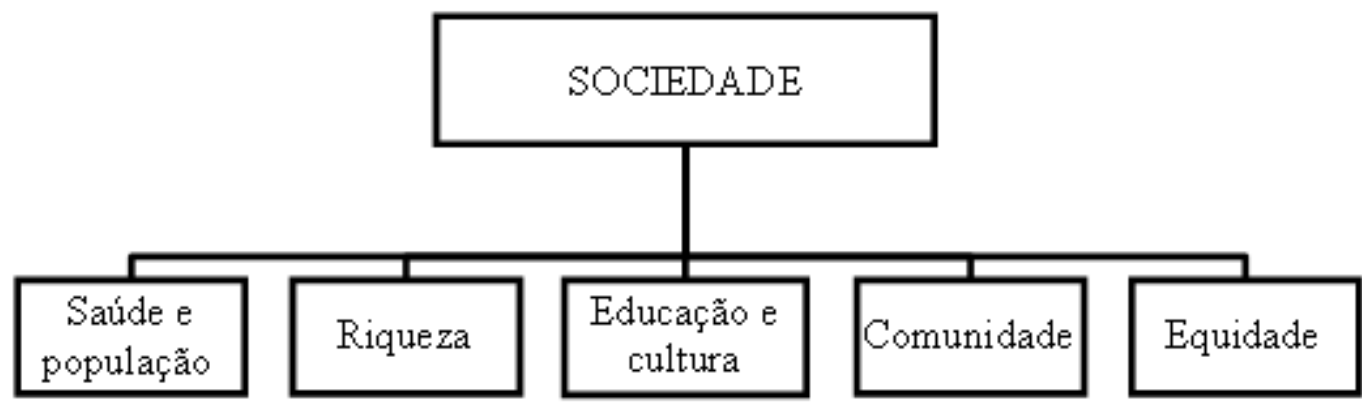

Fluxograma 2: Dimensão social do BST.

Fluxograma 2: social dimension of BST.

Fonte: Cordeiro, 2008; Sanches e Schmidt, 2016.

Source: Cordeiro, 2008; Sanches and Schmidt, 2016.

No tocante à dimensão social, os indicadores são "saúde e população", e se referem a rampas de acessibilidade, piso antiderrapante, apoio a projetos e campanhas contra a exploração infantil, programas e campanhas de saúde para os colaboradores; "riqueza", concernente a questões como a busca por fornecedores locais, oferta de pratos típicos da região e iguarias feitas por produtores locais, 
empregos; o indicador "educação e cultura" investiga se os funcionários são estimulados a conhecerem os atrativos turísticos que compõem o destino, se ofertam cursos de capacitação para a equipe, se há incentivo ao turista para conhecer a cultura local; no indicador "comunidade", as questões são: se utilizam peças de artistas locais na decoração do ambiente, se expõem peças de artesãos da comunidade, se firmam parcerias locais; o indicador "equidade" refere-se ao plano de cargos e carreiras dos colaboradores, apoio a campanhas e projetos contra quaisquer discriminações de cor, gênero e condição social etc.

Cada tópico das dimensões ambiental e social significa um indicador que, integrado ao contexto do empreendimento, complementa a resposta sobre o seu grau de sustentabilidade quanto a esse aspecto. Foi, então, estabelecido um conjunto de práticas, ações e programas referentes aos indicadores como base para avaliar a sustentabilidade no contexto dos empreendimentos, conforme descrito na seção "metodologia" do estudo.

Para a mensuração dos dados e informações obtidas, utilizou-se, então, a metodologia do BST que possibilitou, ao final, a avaliação da sustentabilidade socioambiental nos empreendimentos (Quadro 1):

Quadro 1: Avaliação dos indicadores sociais e ambientais.

Frame 1: Analyze of social and environmental indicators.

\begin{tabular}{|c|c|c|c|}
\hline \multirow{4}{*}{ Dimensão } & $\begin{array}{c}\text { Indicador (peso } \\
\text { individual de 20 } \\
\text { pontos) }\end{array}$ & $\begin{array}{c}\text { Quantidade de } \\
\text { aspectos } \\
\text { avaliados }\end{array}$ & $\begin{array}{c}\text { Pontuação de cada } \\
\text { aspecto (valor do } \\
\text { indicador / no de } \\
\text { aspectos) }\end{array}$ \\
\hline \multirow{4}{*}{ Ambiental } & Terra & 10 & 2,0 \\
\cline { 2 - 4 } & Água & 8 & 2,5 \\
\cline { 2 - 4 } & Ar & 2 & 10 \\
\cline { 2 - 4 } & Etilização de Recursos & 2 & 10 \\
\hline \multirow{4}{*}{ Social } & Sociedade e população & 4 & 1,5 \\
\cline { 2 - 4 } & Riqueza & 4 & 5 \\
\cline { 2 - 4 } & Conhecimento e cultura & 4 & 5 \\
\cline { 2 - 4 } & Comunidade & 4 & 5 \\
\cline { 2 - 4 } & Equidade & 2 & 10 \\
\hline
\end{tabular}

Fonte: Prescott- Allen (2001) e KO (2005) apud Cordeiro, (2008); Sanches e Schmidt (2016), adaptado pelos autores (2018).

Source: Prescott- Allen (2001) and KO (2005) apud Cordeiro, (2008); Sanches and Schmidt (2016), adapted by the authors (2018).

Conforme a análise, foi identificada a quantidade desses aspectos relativos a cada indicador no contexto do empreendimento. Tais aspectos referiram-se às práticas, ações ou programas, assinalados pelo empreendimento enquanto alternativas para as questões apresentadas.

\section{Resultados}

Conforme exposto anteriormente, a amostra foi colhida a partir de mapeamento feito no sistema de ordenação, formalização e legalização de prestadores de serviços turísticos no Brasil, que é o Sistema de Cadastro de Pessoas Físicas e Jurídicas - 
CADASTUR - onde está disponível a quantidade de empreendimentos de hospedagem que atuam na cidade de Barreirinhas e, assim, definiu-se uma porcentagem de $51 \%$ do então universo para coleta dos dados. A técnica utilizada para a coleta foi o questionário de perguntas fechadas e abertas, além da observação in loco. Para tratamento e demonstração dos dados e informações, foram utilizados gráficos, tabelas, representações numéricas e o Barômetro de Sustentabilidade do Turismo - BST, sendo esta a ferramenta utilizada quanto à descrição e avaliação dos aspectos ambientais e sociais nos empreendimentos.

Foi avaliado um total de 53 aspectos correspondentes às esferas ambiental e social do empreendimento, desde tratamento de esgoto (para avaliar o indicador quanto ao uso dos recursos naturais) até planos de cargos e carreiras dos colaboradores (para verificar o indicador da equidade social no empreendimento), por exemplo. Como local de coleta dos dados foi escolhida a cidade de Barreirinhas, que corresponde à área urbana do município, por se tratar de um espaço importante de serviços turísticos na região. Nessa localidade, estão instalados 29 empreendimentos de hospedagem, dos quais foram selecionados 15 para coleta dos dados, que aconteceu no período de 07 a 12 de novembro de 2018, correspondendo a uma amostra de $51 \%$ do universo da pesquisa.

Nesse processo de coleta de dados, importa mencionar as limitações que a pesquisa pode ter sofrido quanto à possibilidade de expressão inexata de algumas respostas frente à realidade do objeto estudado e, também, as dificuldades do estudo diante do receio de alguns agentes em receber o exercício da pesquisa. Por outro lado, considerou-se bastante positiva a receptividade da maioria e a compreensão quanto à contribuição que o estudo pode proporcionar para a melhoria do turismo na cidade.

Os aspectos gerais obtidos na coleta dos dados e das informações permitiram demonstrar a seguinte configuração dos empreendimentos: $93,3 \%$ apresentam entre 3 a 33 unidades habitacionais (UH's) e 6,7\% dispõem de 102 unidades habitacionais; $100 \%$ dos empreendimentos são de categoria independente; $95 \%$ dos colaboradores dos empreendimentos participantes da pesquisa são nascidos em Barreirinhas. contudo, somente $10 \%$ dos colaboradores barreirinhenses ocupam cargos de gestão ou chefia nos empreendimentos.

Quanto à avaliação e análise da sustentabilidade nos empreendimentos, a pesquisa demonstrou que nenhum alcançou a performance desejável quanto aos aspectos socioambientais.

$\mathrm{Na}$ avaliação da perspectiva ambiental, a maioria, 53\%, correspondeu à escala de 21 a 40 pontos, que se refere ao nível potencialmente insustentável, seguido do nível insustentável, ou seja, 33\% dos empreendimentos investigados estão inseridos na escala de 0 a 20 . Somente $14 \%$ encontram-se nos níveis potencialmente sustentável (7\%) e sustentável (7\%), com pontuação de 61 a 80 e 81 a 100, respectivamente.

No que concerne à perspectiva social, a maioria dos empreendimentos investigados, 47\%, está inserida no nível intermediário, isto é, na escala de 41 a 60 pontos, seguido do nível potencialmente insustentável, $27 \%$, com escala entre 21 a 40. Somente $26 \%$ dos empreendimentos apresentaram indicadores positivos, onde $13 \%$ estão inseridos no nível sustentável e $13 \%$ no nível potencialmente sustentável. O fato de que a esfera ambiental demanda uma gestão mais ativa dos empreendimentos quanto aos seus indicadores, o que ocorre em função do uso e 
consumo direto de seus recursos, explica um maior número de aspectos analisados nessa dimensão em comparação com a social e, nesse sentido, a exigência de uma melhor postura sustentável, demonstrada a partir do nível atingido em comparação ao social. Entretanto, essa diferença é irrisória e as duas dimensões apresentam a necessidade de melhor abordagem por parte dos empreendimentos analisados.

Partindo, então, para a demonstração dos indicadores, verificou-se que, em relação à esfera ambiental, os aspectos mais presentes nos empreendimentos foram os correspondentes à "água" e ao "uso dos recursos", cuja recorrência foi verificada nos 15 empreendimentos pesquisados e referentes àquele em 10 dos empreendimentos pesquisados.

Nesse termo, os aspectos mais assinalados quanto ao indicador sustentável da água, foram: revisão constante das instalações hidráulicas, que $60 \%$ dos empreendimentos afirmaram desempenhar, e troca dos enxovais das UH's em períodos superiores a um dia, que também $60 \%$ dos empreendimentos informaram praticar. Os outros aspectos verificados foram os seguintes: máquinas de lavar com consumo eficiente de água (em 40\% dos empreendimentos); descarga de duplo acionamento (20\%); torneiras e chuveiros com regulagem de pressão (20\%); reuso de água para atividades que não necessitam do uso direto de água potável (33\%); e sinalização em áreas do empreendimento referentes ao uso consciente da água (em $27 \%$ dos empreendimentos).

Tratando-se do uso dos recursos naturais, os aspectos mais observados foram: utilização de lâmpadas fluorescentes, ou de LED, em que 14, ou o correspondente a $93 \%$ dos empreendimentos avaliados disseram utilizar, frente ao consumo sustentável da energia; e ar-condicionado e televisores com baixo consumo de energia, que $60 \%$ dos empreendimentos avaliados disseram fazer uso. Os demais aspectos verificados foram: armazenamento e correta destinação do óleo de cozinha (em $40 \%$ dos empreendimentos); temporizadores e sensores de presença (em $27 \%$ ); desligamento automático por cartão (em 20\%); aquecimento de água por placas solares (7\%); geração de energia por painéis solares $(20 \%)$; reutilização de embalagens de vidro, plástico e papel (47\%); aproveitamento da luz e ventilação natural do ambiente (53\%); sinalização em áreas do empreendimento para economia de energia (20\%), e sistema de tratamento de esgoto (em 53\% dos empreendimentos).

Neste caso, um aspecto importante a se destacar é o tratamento de efluentes, ou seja, quanto à existência de tratamento de esgoto no empreendimento. Mais da metade dos pesquisados informaram utilizar sistema de tratamento de esgoto por meio da Companhia de Saneamento Ambiental do Maranhão (CAEMA). Isto representa uma realidade positiva no sentido de minimização e prevenção de danos causados por dejetos lançados de maneira incorreta no ambiente e que podem contaminar rios, lençóis freáticos e mares.

Entretanto, a pesquisa constatou que a outra parte dos empreendimentos (47\%) ainda não dispõe de sistema adequado de tratamento de esgoto. Em Barreirinhas, a questão assume maior relevância por conta do crescimento urbano da cidade e da importância da natureza da região e de sua atratividade turística, com atenção para o Rio Preguiças, que compreende uma notável área onde parte da cidade se estrutura.

Nesse contexto, destaca-se uma ocorrência positiva no universo dos empreendimentos hoteleiros da cidade. Um empreendimento de hospedagem se 
sobressai quanto à sustentabilidade e responsabilidade socioambiental ao acentuar a gestão sustentável ao seu negócio. Dentre os aspectos essenciais referentes à perspectiva socioambiental, o empreendimento apresentou uma prática inovadora que é a construção de uma fossa ecológica. Assim, além de ser um exemplo de contribuição para a preservação ambiental do destino, essa prática reduzirá custos e fortalecerá a marca do estabelecimento quanto ao seu posicionamento sustentável na cidade.

Os demais aspectos relativos aos outros indicadores verificados nos empreendimentos são: coleta seletiva (47\%), medidas para reduzir a produção de resíduos sólidos $(20 \%)$, utilização de refil em vez de sachês nos banheiros (13\%), reciclagem de resíduos sólidos (13\%), utilização de materiais reciclados na decoração $(20 \%)$, redução do consumo de papel (26\%), uso de uniforme de algodão ao invés de nylon (53\%), campanha contra o uso de copos, pratos, canudos e sacolas descartáveis (13\%), utilização de garrafas retornáveis (7\%). Foram ainda investigadas questões como: se o empreendimento utiliza plantas regionais na decoração do ambiente (23\%), se apoia projetos e campanhas para a preservação e cuidado a plantas e animais da região (27\%), se incentiva o uso de transporte e ações alternativas como a bicicleta e a carona solidária (20\%).

No que tange à esfera social, os indicadores de sustentabilidade com maior ocorrência nos empreendimentos de hospedagem em Barreirinhas foram o referente ao conhecimento e à cultura, e o referente à comunidade, os quais foram verificados em $73 \%$ e $67 \%$, respectivamente. Quanto ao indicador "conhecimento e cultura", os principais aspectos demonstrados foram: "incentivo ao turista para conhecer a cultura local", o qual correspondeu a $67 \%$ dos empreendimentos avaliados, e "incentivo aos funcionários para conhecerem os atrativos que compõem o destino" juntamente com "promoção de cursos de capacitação para a equipe", os quais ocorreram em $67 \%$ dos empreendimentos analisados. Os demais aspectos verificados no contexto dos empreendimentos apresentaram-se da seguinte forma: acessibilidade (53\%), programas e campanhas de saúde para os colaboradores (33\%), realização de trabalhos de educação ambiental com hóspedes (26\%), busca por fornecedores locais (53\%), oferta de pratos típicos da região e iguarias feitas por produtores locais $(53 \%)$, apoio a projetos e campanha contra a exploração infantil (7\%), apoio a campanhas e projetos contra quaisquer discriminações de cor, gênero e condição social etc. (33\%), exposição de peças de artesãos da comunidade (73\%).

Quanto aos benefícios advindos de práticas sustentáveis, $60 \%$ dos empreendimentos citaram benefícios gerados em função dessa adoção. $45 \%$ das respostas apontaram como benefício o retorno financeiro para o empreendimento, sendo citado como redução de custos, inovação e tecnologia, que proporcionam melhor desempenho ao empreendimento; $11 \%$ citaram benefícios relacionados à credibilidade da marca por meio do desempenho de uma postura sustentável o que, nesse sentido, possibilita maior atração de clientes; e 44\% citaram benefícios relacionados à responsabilidade socioambiental, que contribui para o melhor desenvolvimento da atividade e do destino, promovendo, por conseguinte, boa reputação e diferenciação à empresa.

Do ponto de vista dos entrevistados sobre a percepção dos hóspedes quanto à adoção de uma postura sustentável no empreendimento, $60 \%$ responderam haver uma preocupação média; 26,7\% informaram haver uma preocupação baixa; 6,7\% informaram haver uma preocupação alta; e outros $6,7 \%$ informaram haver uma preocupação muito alta do hóspede quanto à adoção de práticas sustentáveis no 
empreendimento. Quanto a isso, alguns dos questionados responderam que essa preocupação é mais perceptível em hóspedes de origem estrangeira.

\section{Discussão dos Resultados}

A partir dos resultados, foi verificado que a adoção de práticas sustentáveis no empreendimento de hospedagem assume uma importância relativa à preocupação dos hóspedes quanto a adoção ou não dessas práticas. Ao mesmo tempo em que não se obteve uma demonstração expressiva referente ao nível "alto" ou "muito alto" de preocupação desses clientes, verificou-se, por outro lado, que não houve nenhum posicionamento alheio a essa problemática, ou seja, nenhum dos questionados mencionou haver "nenhuma" preocupação desse grupo frente à sustentabilidade nos empreendimentos. Juntamente a essa realidade, um dos questionados mencionou 0 fato de que essa preocupação é mais perceptível em turistas estrangeiros. Portanto, infere-se, a partir da demonstração, que a adoção de práticas sustentáveis no empreendimento influencia, em algum nível, o cliente, chegando até o nível muito alto de preocupação, e que isso representa a existência de uma demanda a ser trabalhada.

Após a demonstração dos benefícios, buscou-se compreender os desafios que os empreendimentos apresentaram em relação à adoção de uma postura sustentável. Nesse sentido, 60\% dos entrevistados informaram haver alguma dificuldade. Destes, $60 \%$ citou a necessidade de apoio do poder público quanto a atividades e ações importantes de sustentabilidade e, nesse contexto, citaram com unanimidade, um problema relacionado à coleta seletiva. Os entrevistados afirmaram não haver efetividade da ação de separação de resíduos no empreendimento para a coleta seletiva, uma vez que o órgão público responsável por essa coleta não direciona corretamente esses resíduos. Este fato demonstra, assim, um problema referente à sustentabilidade do local, pois, a má destinação e a má gestão dos resíduos sólidos provocam fortes impactos ao meio ambiente. Portanto, é necessário que se desenvolvam alternativas na cidade quanto ao tratamento desses resíduos e, nesse sentido, a reutilização, redução e reciclagem tornam-se importantes medidas para a minimização dos impactos que podem ser gerados ao meio ambiente. Assim, embora $47 \%$ dos empreendimentos tenham citado realizar a coleta seletiva, questiona-se a efetividade desta ação diante da falta de apoio do órgão público mencionada pelos entrevistados.

Ainda nessa abordagem, foram citados como desafios na adoção do conceito sustentável no empreendimento: a falta de apoio da comunidade local (em $20 \%$ das respostas). Foi citada também a deficiência na educação formal e qualificação profissional na localidade; práticas prejudiciais ao meio ambiente, como a cultura de incineração; e a falta de uma rede de produtores locais para fornecimento de produtos e alimentos. Concluindo essa questão, 10\% responderam sentir dificuldades relacionadas à falta de apoio, tanto do poder público quanto do próprio setor privado no destino, e 10\% mencionaram dificuldades em função da necessidade de melhor organização, ou parceria, dos três poderes: público, civil e privado.

Por meio dessa abordagem foi possível compreender que os empreendimentos têm a necessidade de um melhor relacionamento junto aos stakeholders e que isso impacta no desempenho social e ambiental do empreendimento, isto é, em sua sustentabilidade. Assim, ações ligadas à atuação do poder público, como coleta seletiva e sistema de tratamento de esgoto afetam diretamente o ambiente do 
empreendimento e influenciam a sua capacidade sustentável. Também, a qualidade da educação formal e qualificação profissional no local reflete diretamente a perspectiva social do empreendimento ao prestar um serviço de melhor qualidade e mais sustentável, com a contribuição dos colaboradores locais. Cita-se também a importância dos fornecedores locais para o empreendimento, como produtores de alimentos e produtos regionais, visto que essa relação possibilita benefícios como menor custo na aquisição desses produtos, assim como a ampliação de sua oferta e valor.

Portanto, dada a avaliação e descrição da perspectiva socioambiental nos meios de hospedagem em Barreirinhas, pôde-se verificar que essa visão é importante para esses empreendimentos, pois tem a capacidade de influenciar aspectos essenciais em sua cadeia de valor. Destarte, os aspectos mencionados corresponderam à redução de custos dos serviços e atividades, diferenciação da marca no mercado a partir de uma postura sustentável e atração de clientes orientados pela preocupação e ética sustentável.

Por outro lado, concomitante à menção de tais benefícios e à adoção de importantes práticas sustentáveis, foi constatado ainda um desempenho incipiente do fator sustentável nesses empreendimentos, relacionado aos aspectos ambiental e social. Dentre os desafios mencionados para desenvolvimento da postura sustentável, os empreendimentos apresentaram, principalmente, aspectos relacionados ao contexto externo da organização, mas que influenciam diretamente em seu desempenho. Assim, é demonstrada a necessidade de maior parceria e relacionamento entre os setores e agentes da atividade turística, compreendendo os stakeholders do empreendimento.

\section{Considerações Finais}

A partir desse estudo, ficou demonstrado que a perspectiva socioambiental exerce influência em aspectos importantes nos meios de hospedagem da cidade de Barreirinhas, atuando como estratégia de valor para esses empreendimentos, e gerando benefícios significativos. Isso ocorre, principalmente, na utilização dos recursos naturais que refletem na diminuição de custos e na eficiência das atividades. Foram constatadas outras formas pelas quais essa geração de valor pode ocorrer, como por meio da diferenciação da marca do empreendimento no mercado e da captação de demanda por nichos.

Verificou-se, assim, que as práticas socioambientais promovem valor ao empreendimento por meio dessas formas principais: liderança ou predominância por meios dos custos; diferenciação no mercado; e captação de demandas por nichos. Dentre as vantagens principais, as empresas que adotam tais práticas têm seus custos reduzidos e fornecem melhores serviços, adquirindo, deste modo, competitividade no mercado; também fortalecem sua marca, gerando uma imagem positiva do estabelecimento e, consequentemente, se diferenciando no setor; além da possibilidade de atrair mais hóspedes ao desenvolverem um perfil que é relevante para clientes que levam em consideração o conceito da sustentabilidade.

Mencionando os aspectos passíveis de melhoria no contexto dos empreendimentos hoteleiros de Barreirinhas, constatou-se que esses equipamentos têm a necessidade de um melhor relacionamento junto aos stakeholders, compreendidos enquanto fornecedores, comunidade e órgãos parceiros, o que 
influencia o valor dos serviços e na sustentabilidade do turismo na localidade. Quanto a isso, os meios de hospedagem demonstraram-se dependentes da atuação conjunta de órgãos ou agentes fundamentais para o desempenho e para o desenvolvimento sustentável da atividade turística, dentre os quais se demonstrou de forma significativa a atuação do setor público.

Também foi verificado, a partir da avaliação realizada, que o nível de sustentabilidade ainda não atingiu a performance desejada nos empreendimentos hoteleiros da cidade, visto que tais estabelecimentos apresentam diversos aspectos passíveis de melhoria. Constatou-se que muitos deles influenciam diretamente sua competitividade e sustentabilidade e, portanto, demonstram-se necessários para seus serviços, assim como para a atividade turística da região. Assim, compreende-se a importância da perspectiva socioambiental e, portanto, da sustentabilidade para os empreendimentos de hospedagem da cidade, uma vez que se torna necessário para a oferta de seus serviços e consequentemente, para a oferta dos produtos turísticos do destino. Para tanto, deve-se empregar uma atenção maior ao propósito de gerar valor aos empreendimentos e ao desenvolvimento turístico e sustentável da região. Nesse ínterim, o turismo sustentável se coloca como um fator de desenvolvimento econômico e social da região, contribuindo para a melhoria da qualidade de vida da população assim como para a qualidade de seu ambiente e patrimônio natural.

Ademais, orienta-se o desenvolvimento de mais estudos relacionados à temática, assim como relacionados ao campo da pesquisa, pois ainda há muito a se construir e contribuir para o turismo da região e do estado. Assim, quanto mais base de informações e conhecimento houver, melhor será para o progresso de uma sociedade mais informada e, portanto, mais sustentável, onde o turismo assume destaque enquanto atividade essencial à capacidade e à arte de viver bem.

\section{Referências}

ALMEIDA, I.D.; ABRANJA, N.A. Turismo e sustentabilidade. Cogitur, Journal of Tourism Studies, Lisboa, n. 2, 2009. Disponível em: <http://recil.grupolusofona. pt/handle/10437/1874 > . Acesso em: 20 set. 2018.

ALMEIDA, R.L. et al. Hotelaria e turismo sustentável: estudo de caso em uma pousada na cidade de Tiradentes/MG. In: Simpósio de Excelência em Gestão e Tecnologia, 10, 2013, Resende - RJ. Anais eletrônicos [...]. Resende - RJ: Associação Educacional Dom Bosco. Disponível em:<https://www.aedb.br/seget/ arquivos/artigos13/15918643.pdf>. Acesso em: 5 nov. 2018.

BACHA, M.L.; SANTOS; J.; SCHAUN, A. Considerações teóricas sobre o conceito de Sustentabilidade. Simpósio de Excelência em Gestão e Tecnologia, 7., 2010, Resende - RJ. Anais eletrônicos [...]. Resende - RJ: Associação Educacional Dom Bosco. 14 p. Disponível em: <https://www.aedb.br/seget/arquivos/artigos10/31 cons\%20teor\%20bacha.pdf >. Acesso em: 10 set. 2018.

BRASIL. Decreto no $\mathbf{8 6 . 0 6 0}$, de 2 de junho de 1981. Cria, no Estado do Maranhão, o Parque Nacional dos Lençóis Maranhenses, com os limites que especifica e dá outras providências Brasília, DF: Diário Oficial da União. Disponível em: <http://www2.camara.leg.br/legin/fed/decret/1980-1987/decreto-86060-2-junho-1981435499-publicacaooriginal-1-pe.html>. Acesso em: 13 out. 2018. 
BRASIL. Lei no 11.771, de 17 de setembro de 2008. Dispõe sobre a Política Nacional de Turismo, define as atribuições do Governo Federal no planejamento, desenvolvimento e estímulo ao setor turístico; revoga a Lei no 6.505, de 13 de dezembro de 1977, o Decreto-Lei № 2.294, de 21 de novembro de 1986, e dispositivos da Lei no 8.181 , de 28 de março de 1991; e dá outras providências. Brasília, DF: Presidência da República, 2008. Disponível em: $<$ http://www.planalto.gov.br/ccivil 03/ ato2007-2010/2008/lei//11771.htm>. Acesso em: 26 set. 2018.

BRASIL. Lei no 9.985, de 18 de julho de 2000. Regulamenta o art. 225, § 10, incisos I, II, III e VII da Constituição Federal, institui o Sistema Nacional de Unidades de Conservação da Natureza e dá outras providências. Brasília, DF, 18. jul. 2000. Disponível em: <http://www.planalto.gov.br/ccivil 03/LEIS/L9985.htm>. Acesso em: 15 out. 2018.

CARDOSO, M.L.; FIGUEIREDO, M.D. Práticas de inovações sustentáveis: estudo qualitativo no setor hoteleiro em Fortaleza/CE. Caderno Virtual de Turismo, Rio de Janeiro, v. 16, n. 1, p. 46-59, abr. 2016.

CORDEIRO, I.J.D. Instrumentos de avaliação da sustentabilidade do turismo: uma análise crítica. 2008. 15 f. Dissertação - (Mestrado em Ordenamento do Território e Planejamento Ambiental) - Faculdade de Ciências e Tecnologia, Universidade Nova de Lisboa, Lisboa, $2008 . \quad$ Disponível em:<https://run.unl.pt/bitstream/10362/1921/1/Cordeiro 2008.pdf>. Acesso em: 15 out. 2018.

DIAS, R. Turismo sustentável e meio ambiente. São Paulo: Atlas, 2007. 208 p.

DIAS, R.G. Tempo de muito chapéu e pouca cabeça, de muito pasto e pouco rastro: ação estatal e suas implicações para comunidades tradicionais no Parque Nacional Dos Lençóis Maranhenses. 2017. 193 f. Tese - (Doutorado em Ciências Sociais) Faculdade de Ciências Sociais, Universidade Federal do Maranhão, São Luís, 2017. Disponível em <https://tedebc.ufma.br/jspui/bitstream/tede/1998/2/ROSEANEDIAS. pdf> Acesso em: 19 nov. 2018.

FEIL, A.A.; SCHREIBER, D. Sustentabilidade e desenvolvimento sustentável: desvendando as sobreposições e alcances de seus significados. Cad. EBAPE. BR, Rio de Janeiro, v. 14, n. 3, p. 667-681, jul./set. 2017.

FREITAS, N.R. et al. As discussões sobre a sustentabilidade na atividade turística: uma análise para o Brasil na última década. El Periplo Sustentable, [S.I.], n. 27, p. 54-91. 2014.

GRAÇA, I.M. Barreirinhas em tempo de mudança: reconstrução de identidades nas rotas do turismo. Aveiro: Universidade de Aveiro, 2010. 371 p.

HANAI, F.Y. Desenvolvimento sustentável e sustentabilidade do turismo: conceitos, reflexões e perspectivas. Revista Brasileira de Gestão e Desenvolvimento Regional - G\&DR, Taubaté, v. 8, n. 1, p. 198-231, jan./abr. 2012.

IBAMA. Plano de manejo dos Lençóis Maranhenses. Brasil, 2003. Disponível em: $<$ http://www.icmbio.gov.br/parnalencoismaranhenses/planos-de-manejo.html>. Acesso em: 26 out. 2018.

MARTINS, É.M. Desenvolvimento local e atividade turística em Barreirinhas: cidade portal dos Lençóis Maranhenses. 2008. 131 f. Dissertação (Mestrado em Geografia) 
- Faculdade de Geografia, Meio Ambiente e Desenvolvimento, Universidade Estadual de Londrina, Londrina. 2008.2 Disponível em: <http://www.uel.br/projetos/ternopar/pages/arquivos/dissertacao\%20Erica.pdf> Acesso em out. 2018.

MINISTÉRIO DO TURISMO (Brasil). Programa de regionalização do turismo: diretrizes. Brasília, DF, 2013. 47 p. Disponível em: $<$ http://www.turismo.gov.br/images/programas acoes home/PROGRAMA DE REGI ONALIZACAO DO TURISMO - DIRETRIZES.pdf>. Acesso em: 22 set.2018.

MINISTÉRIO DO TURISMO (Brasil). Plano Nacional de Turismo 2018 - 2022: mais emprego e renda para o brasil. Brasília, DF, 2018. 160 p. Disponível em: $<$ http://www.turismo.gov.br/images/MTur-pnt-web2.pdf>. Acesso em: 22 set.2018.

MINISTÉRIO DO TURISMO (Brasil). Glossário do turismo: compilação de termos publicados por Ministério do Turismo e Embratur nos últimos 15 anos. Brasília, DF, 2018. 44 p. Disponível em: <http://www.turismo.gov.br/images/pdf/Publica\%C3\%A7 \%C3\%B5es/Glossario do Turismo - 1\%C2\%AA \%20edi\%C3\%A7\%C3\%A3o.pdf>.

Acesso em: 16 nov. 2018.

MIRANDA, A.L. Vantagem competitiva em pequenos negócios: perspectivas à luz das capacidades dinâmicas: caso São Luís. 2017. 203 f. Tese - (Doutorado em Gestão) Faculdade de Gestão, Instituto Universitário de Lisboa (ISCTE - IUL), Lisboa. 2017. Disponível em: <https://repositorio.iscte-iul.pt/bitstream/10071/16105/ 1/anderson lourenco oliveira tese doutoramento.pdf $>$. Acesso em: 16 nov. 2018.

NEVES, J.R.O. O Papel dos eventos no reforço da atractividade turística de Cabo Verde: (o caso da cidade da praia). 2012. 147 f. Dissertação (Mestrado em Turismo) - Escola Superior de Hotelaria e Turismo do Estoril, Estoril, 2012. Disponível em: <https://comum.rcaap.pt/bitstream/10400.26/4454/1/2012.04.017 .pdf> Acesso em: 15 out. 2018.

OLIVEIRA, M.A.S.; ROSSETTO, A.M. Modelo Integrado de Sustentabilidade e Competitividade em Meios de Hospedagem [MISCMH]. Revista Rosa dos Ventos Turismo Hospitalidade, v. 6, n. 4, p. 546-563, out./dez, 2014

PORTO, R.B.; SANTOS, P.M.F. A gestão ambiental como fonte de vantagem competitiva sustentável: contribuições da visão baseada em recursos e da teoria institucional. Revista de Ciências da Administração, v. 15, n. 35, p. 152 - 167, abr. 2013.

PRODANOV, C.C.; FREITAS, E.C. Metodologia do trabalho científico: métodos e técnicas da pesquisa e do trabalho acadêmico. 2. ed. Rio Grande do Sul: Universidade FEEVALE, 2013. 276 p. Disponível em: <http://www.feevale.br/Comum/midias/8807f05a-14d0-4d5b-b1ad-1538f3aef538/Ebook\%20Metodologia\%20do\%20Trabalho\%20Cientifico.pdf>. Acesso em22. nov. 2018.

PROGRAMA DAS NAÇÕES UNIDAS PARA O DESENVOLVIMENTO. INSTITUTO DE PESQUISA ECONỔMICA APLICADA. FUNDAÇÃO JOÃO PINHEIRO. Atlas do desenvolvimento humano do Brasil. Disponível em: <http://www.atlasbrasil.org.br/2013/pt/perfil uf/maranhao >. Acesso em: 22 out. 2018. 
REIS, A.R.V. A importância do desenvolvimento sustentável do turismo uma experiência didática no 8.ำ ano de escolaridade. 2015. 251 f. Dissertação (Mestrado em Ensino de História e Geografia no 3. Ciclo do Ensino Básico e Ensino Universidade de Lisboa, Lisboa, 2015. 251 p. Disponível em: <http://repositorio.ul.pt/handle/10451/22734>. Acesso em: 22. nov. 2018.

RODRIGUES, L.M. Os sentidos do lugar turístico no discurso da propaganda oficial sobre os Lençóis Maranhenses. São Luís: EDUFMA, 2013. 214 p.

SANCHES, F.C.; SCHMIDT, C.M. Indicadores de sustentabilidade ambiental: uma análise das práticas sustentáveis em empreendimentos de turismo rural. Desenvolvimento em Questão, v. 14, n. 37, p. 89-114, 30 nov. 2016.

SANTOS, G.S.; SANTOS, A.A.P.; SEHNEM, S. Como mensurar a sustentabilidade?: um estudo das principais técnicas e indicadores. Revista Organizações e Sustentabilidade, Londrina, v. 4, n. 1, p. 3 - 48, jan./jun. 2016.

\section{Notas:}

' Stakeholder é um termo inglês referente a uma determinada empresa ou negócio em que stake significa interesse, participação, risco, e holder significa aquele que possui. Assim, stakeholder pode significar também partes interessadas, sendo pessoas ou organizações que podem ser afetadas pelos projetos e processo de uma empresa. Conceito adaptado do Portal Administração. Disponível em: <http://www.portal-administracao.com/2014/07/ stakeholderssignificado-classificacao.html> Acesso em 18 de novembro de 2018.

i Disponível em: <https://cidades.ibge.gov.br/brasil/ma/barreirinhas >. Acesso em outubro de 2018.

iii Disponível em <http://www.atlasbrasil.org.br/2013/pt/perfil m/barreirinhas ma>. Acesso em: 15 out. 2018.

iv Disponível em:

$<$ http://qv.icmbio.gov.br/QvAJAXZfc/opendoc2.htm?document=painel corporativo 6476.qvw\& host=Local\&anonymous=true $>$. Acesso em:15 de novembro de 2018.

${ }^{\text {}}$ Disponível em: <https://cadastur.turismo.gov.br/hotsite/\#!/public/capa/entrar>. Acesso em 15 de novembro de 2018.

Rosélis de Jesus Barbosa Câmara: Universidade Federal do Maranhão, São Luis, MA, Brasil.

E-mail: zelis.camara@yahoo.com.br

Link para o currículo Lattes: http://lattes.cnpq.br/1995690638678298

Raimunda Rocha Reis: Universidade Federal do Maranhão, São Luis, MA, Brasil.

E-mail: rochareis.raimunda@gmail.com

Link para o currículo Lattes: http://lattes.cnpq.br/9730392099600818

Rozuila Neves Lima: Universidade Federal do Maranhão, São Luis, MA, Brasil. 
E-mail: rozuila@hotmail.com

Link para o currículo Lattes: http://lattes.cnpq.br/4654403359646517

Data de submissão: 28 de setembro de 2019

Data de recebimento de correções: 30 de setembro de 2019

Data do aceite: 30 de setembro de 2019 